UNIVERSITY of NORTH FLORIDA.

\section{Journal of Counseling Sexology \& Sexual} Wellness: Research, Practice, and Education

\title{
Consensual Qualitative Research of LGB Persons' Counseling Experiences Addressing Religious/Spiritual Foci
}

Kristopher M. Goodrich

University of New Mexico

Melissa Luke

Syracuse University

Follow this and additional works at: https://digitalcommons.unf.edu/jcssw

Part of the Student Counseling and Personnel Services Commons

\section{Recommended Citation}

Goodrich, K. M., \& Luke, M. (2019). Consensual Qualitative Research of LGB Persons' Counseling Experiences Addressing Religious/Spiritual Foci. Journal of Counseling Sexology \& Sexual Wellness: Research, Practice, and Education, 1 (1). https://doi.org/10.34296/01011003

This Article is brought to you for free and open access by the Brooks College of Health at UNF Digital Commons. It has been accepted for inclusion in Journal of Counseling Sexology \& Sexual Wellness: Research, Practice, and Education by an authorized administrator of UNF Digital Commons. For more information, please contact Digital Projects.

(C) 2019 All Rights Reserved 


\title{
Consensual Qualitative Research of LGB Persons' Counseling Experiences Addressing Religious/Spiritual Foci
}

\author{
Kristopher M. Goodrich \\ University of New Mexico
}

\author{
Melissa Luke \\ Syracuse University
}

\begin{abstract}
This article reports a Consensual Qualitative Research (CQR) analysis of the experiences of 12 participants who identified as LGB and received counseling that addressed religious/spiritual foci. Participants identified two primary and intersecting themes including an increased sense of agency and locus of control, as well as increased cognitive flexibility. Additional subthemes included manifestation of agency and locus of control intrapersonally, interpersonally, and globally. Subthemes of cognitive flexibility were also identified intrapersonally, interpersonally, and globally. Implications are discussed for counseling, counselor education, and future research.
\end{abstract}

Keywords: agency, locus of control, cognitive flexibility, LGB, CQR, spirituality, religion

\section{Introduction}

Sexuality is expressed in many forms throughout the lifespan, and one dimension of sexuality is sexual/affectional identity. For two decades, research has explored challenges to identity integration within lesbian, gay, and bisexual (LGB) individuals who also identify as religious. Although studies have increasingly sought to explore the process of identity integration, including how it takes place, few scholars have connected the ways in which personal agency, locus of control, or cognitive flexibility may have influenced the identity development process in LGB clients. The current article aims to explore the experiences of LGB clients who address religious/spiritual foci in their counseling. We decided to utilize a religious/spiritual frame for the study because some clients subscribe to a particular tradition or organized group (i.e., religious), while other clients identify as having a more personal relationship or experience with themselves and/or the universe. In doing so, the article describes how these variables may influence and interact with one another to support LGB persons in their identity integration experience when having completed counseling experiences which focused on clients' sexual and religious/spiritual identities. The overarching goal of the project was to better understand multiple identity development and integration to provide counselors greater insight into how to better support their clients' sexual, and overall, wellness.

\section{Literature Review}

Literature related to religious/spiritual counseling with LGB persons is robust and is continuing to expand. In a recent qualitative study with 35 lesbian, gay, bisexual, transgender, and queer (LGBTQ) participants, Beagan and Hattie (2015) noted a myriad of emotional, psychologi- cal, and behavioral consequences of conflicts between sexual/affectional identity and spiritual/religious identities, including "shame, guilt, sex negativity, disconnection from body, and severing of relationships to self and others" (p. 98). Furthermore, in their review of the literature, Anderton, Pender, and Asner-Self (2011) noted that LGB individuals have frequently attempted to resolve such conflicts between sexual/affectional and religious identities by changing their religious environment, through

disaffiliating from congregations or religions that were nonaffirming of their LGB identity; attending/becoming members of a 'para-church organization' (Pitt, 2010, p. 58), new congregations, or religions; focusing on the development of a spiritual identity rather than a religious one; or abandoning religion or spirituality altogether (p. 268).

Researchers have concurrently identified myriad negative consequences of LGBTQ persons' rejecting their religious identities, including increased and ongoing psychological distress (Dehlin, Galliher, Bradshaw, \& Crowell, 2015;

\begin{tabular}{|c|}
\hline Corresponding Author \\
\hline Kristopher M. Goodrich \\
University of New Mexico \\
MSC05-3040 \\
1 University of New Mexico \\
Albuquerque, NM 87131 \\
E: kgoodric@ unm.edu \\
P: (505)277-4063 \\
\hline
\end{tabular}


Lalich \& McLaren, 2010), a process described by Green, Murphy, and Blumer (2010) as "irreconciliation" (p. 248).

There is other research that supports positive aspects and protective factors associated with identifying as both LGBTQ and religious/spiritual (Rosenkrantz, Rostosky, Riggle, \& Cook, 2016; Rostosky, Danner, \& Riggle, 2010). It is therefore not surprising that many LGBTQ individuals who identify as religious have reported an attempt to develop a spiritual identity that is ostensibly less conflictual with their LGBTQ identity (Anderton et al., 2011; Bowland, Foster, \& Vosler, 2013; Bozard \& Sanders, 2011; Dahl \& Galliher, 2012; Pitt, 2009, 2010). Nonetheless, overall LGB individuals report high levels of minority stress (Brewster, Moradi, DeBlaere, \& Velez, 2013; Crowell, Galliher, Dehlin, \& Bradshaw, 2014), which may contribute to their seeking counseling services at disproportionately higher rates than their heterosexual peers (Luke \& Goodrich, 2015). There has been minimal previous research that has sought to understand the identity development process that may take place as part of the experiences of LGB persons who seek to integrate their religious/spiritual and affectional identities while in counseling. Therefore, findings from the current research may assist counselors to better serve future clients that may come to counseling with similar concerns.

\section{Cognitive Development}

Cognitive development is understood as a movement from a dualistic, objectivistic view of knowledge to a more subjective, relativistic view, and then to a constructivist view of knowledge (Hofer \& Pintrich, 1997; Perry Jr., 1970, 1998). Streufert and Swezey (1986) defined cognitive complexity as the extent to which individuals differentiate and integrate information and as a sub-component, cognitive flexibility as an awareness of "options and alternatives" and an ability "to be flexible and adapt" (Kim \& Omizo, 2006, p. 247). Recent research, however, has supported that cognitive complexity is not static, and it can vary from context to context (Brendel, Kolbert, \& Foster, 2002; Granello, 2002; Welfare $\&$ Borders, 2010). Although research on cognitive development and cognitive flexibility have yet to examine their role in the identity development process of LGB persons, it seems reasonable that cognitive flexibility may play a role in the identity adjustment process for LGB persons. We believe in this connection between cognitive flexibility and identity development as identity development has often been referenced as an adaptive process when one considers new alternatives while attempting to resolve identity conflicts between multiple (e.g., religious/spiritual and sexual) identities. As cognitive flexibility has been associated with positive mental health outcomes broadly (e.g., Brewster et al., 2013), we deduced that cognitive flexibility might play a role in identity development more specifically.

\section{Personal Agency}

Although there is a large literature exploring how autonomy is related to motivation (Deci, Hodges, Pierson, \& Tomassone, 1992; Thompson \& Luke, 2016), extant research has not explored the process of personal agency in LGB persons within the counseling process. Bandura (2001) has described agency as the capacity for human beings to be able to make discerning choices. Within Marxist philosophy, agency involves making both attributions and resultant choices independent from any structural factors (such as social class, but also religion, spirituality, gender, ethnicity, or sexualaffectional identity) that may impose social or other valueladen constraints on one's thinking or behavior. Related to agency, locus of control (Rotter, 1954) is the extent to which individuals believe that they can control events that affect them. Though not an either-or orientation, research has explored differences in internal and external locus of control orientations across age, gender, religion, and other identity factors (Aldwin, Igarashi, Gilmer, \& Levenson, 2017; Holt, Clark, Kreuter, \& Rubio, 2003; Schultz \& Schultz, 2004). In general, findings support that a more internalized locus of control and increased agency is associated with positive mental health outcomes (Aldwin et al., 2017; Brewster et al., 2013; Carter, Mollen, \& Smith, 2014; Holt et al., 2003; Schultz \& Schultz, 2004). Therefore, it is plausible that part of the counseling process related to identity integration may have contained both cognitive flexibility and locus of control. Religion or spirituality might be a process that happens to a client, based upon their family of origin, in which they do not have investment or control; this is an example of external locus of control. Conversely, individuals may elect to further invest in their religion/spirituality from their family of origin, or find an identity on their own; this internally motivated process serves as an example of internal locus of control. We were interested to understand more about how participants in our study might express their locus of control in relation to their religious or spiritual experiences.

Despite the increasing awareness in the counseling and counselor education practice literature of the salience of religious/spiritual identity for LGB persons within counseling (Kocet, Sanabria, \& Smith, 2011), there have been limited studies that have examined the role of professional counseling as part of identity integration (Buser, Goodrich, Luke, \& Buser, 2011). Despite the need for more research in this area, studies do suggest that the counseling context may reflect similar homophobia and heterosexism as has been documented more broadly in society (Nadal, Skolnik, \& Wong, 2012; Porter, Hulbert-Williams, \& Chadwick, 2014). For example, Shelton and Delgado-Romero (2011) found that LGBTQ clients reported having experienced a variety of identity related micro-aggressions in counseling. This work is supported by participants in past research (Buser et al., 2011; Goodrich, Buser, Luke, \& Buser, 2016), who although 
did not label them as micro-aggressions, noted a range of negative and disaffirming experiences with counselors related to both their LGBTQ and religious identities. In a phenomenological qualitative study of seven gay men, McGlasson and Rubel (2015) noted that counseling interventions were most often aligned with the counselor's values and not those of the client. As this finding is in contradiction with the ethical imperative to operate from the cultural, religious, worldview of the client (American Counseling Association, 2014; Luke, Goodrich, \& Gilbride, 2013), counselors may find post-modern theories of counseling provide a beneficial framework to address religious/spiritual issues with LGB clients (Sherry, Adelman, Whilde, \& Quick, 2010).

Although the ameliorative role of counseling in the process of identity integration is intuitive, the limited research is only beginning to identify the specific counseling elements, interventions, and processes that may occur as part of identity integration. In their narratology of LGBT clients' experiences addressing religious and spiritual issues in counseling, Buser et al. (2011) identified examples of individuals' positive counseling experiences, as well as participants' ability to reframe counselors' responsibility. In addition, in a subsequent Consensual Qualitative Research (CQR) analysis, Goodrich et al. (2016) found that self-acceptance, the centrality of religious or spiritual concerns to the goal of counseling, identification with the counselor, and the counseling environment were all part of the identity integration that took place. Taken together, these findings suggested that as of yet unidentified developmental processes might be occurring within counseling that merit further examination. Other research demonstrated how lower levels of locus of control are related to LGB individuals' psychological distress (Carter et al., 2014), while higher levels of bi-cultural self-efficacy and cognitive flexibility can promote mental health (Brewster et al., 2013). Therefore, a more thorough examination of clients' report of how agency, locus of control, and cognitive flexibility may manifest as part of the counseling experiences of clients who identified as LGB and received counseling that addressed religious/spiritual issues is warranted. Therefore, the purpose of this study was to qualitatively explore the experiences of LGB persons who experienced religious/spiritual counseling in an effort to better understand their multiple identity development and integration while engaged in the counseling process. The goal of the project was to provide counselors and counselor educators greater insight in how to support their clients' sexual, and overall, wellness through the counseling process when their clients seek identity integration.

\section{Methods}

We utilized Consensual Qualitative Research (CQR) for the design of the study as it is a collaborative methodology that allows for participants' experiences to inform the- ory and supports greater applicability for the findings (Hays \& Wood, 2011; Hill, 2011). The method utilizes a coding team with attention to variance across identity and perspectives as a means to increase trustworthiness. Finally, it allows researchers to identify and present domains or categories across frequency levels, allowing presenters to present data reflecting general (all or in one case), typical (more than half of the cases), and variant (at least two cases; Goodrich et al., 2016; Hays \& Wood, 2011; Hill, 2011). Doing so enables researchers to present participants' shared and unique experiences, whereas other methodologies use higher order axial themes that can diminish unique voices or experiences. Since there are multiple subgroups and voices in the larger LGB community, voice is particularly salient. Therefore, the current researchers selected CQR so as not to minimize the potential multiplicity in voice and complexity in perspective that could be lost if only soliciting one community viewpoint (Goodrich et al., 2016; Hill, 2011). Data for the study was analyzed and coded while conducting a previous study on this topic (Goodrich et al., 2016); however, due to space limitations, it was not able to be included in the previous study. The findings in the current study provide additional reflections shared by participants, beyond what was shared in prior studies, and reflects different ways in which they understood their identity integration process.

\section{Participants}

Twelve persons participated in the study, all of whom identified as white and cisgender. Eight participants identified as female, and four identified as male. All men identified as gay; of the female participants, six identified as lesbian, and two as bisexual. Regarding religious/spiritual identity, nine participants defined themselves as Christian (e.g., Lutheran, Mormon, Presbyterian, Roman Catholic) and three identified themselves as primarily spiritual. It should be noted that when completing demographic forms, some participants were specific to identify their religious/spiritual identity in terms of the identity from their childhood, whereas others made note that they identified them in terms of their current religious/spiritual identity. Participants currently resided in locations across the continental United States. All participants have been provided pseudonyms to protect their identities.

\section{Procedures}

In this study, we were interested in exploring the experiences of participants who identified as LGB and received counseling that addressed religious/spiritual issues while in counseling. We received IRB approval from our universities before the commencement of the study. Recruitment messages were solicited on two professional counseling association listservs. Members of the listservs were asked to share the study solicitation with clients that appeared to meet 
the recruitment protocol. The recruitment message was also shared with university practicum and internship locations (i.e., clinical mental health counseling settings), and snowball sampling was employed; snowball sampling consisted of researchers asking participants who completed the study to identify further eligible participants.

Potential participants were instructed to contact the first author. He screened potential participants for eligibility for the study, as well as processed the written consent forms. At this time, participants were informed that they would participate in an interview that would be audiotaped for later transcription. Following receipt of the signed consent form, the first author assigned the participant to be interviewed by one of three interviewers. The interviews all occurred using a semi-structured interview guide, which was adapted from the Knox, Catlin, Caspter, and Scholosser (2005) study. Example questions included the following: How has your religious identity evolved, shifted or changed? Stayed the same? How has your LGBTQ identity evolved, shifted or changed? Stayed the same?

\section{Postitionality}

Prior to engagement in the qualitative research, we found it important to explore and identify our potential biases and reactions that could have been relevant to the study (Hays \& Singh, 2011). Although the current study only has two authors, the original research team wherein the data was collected consisted of four persons: three interviewers and an auditor. Two members of the original team identified as white heterosexual women, one as a white heterosexual male, and one as a white gay man. All identified as white and were employed as counselor educators in tenured or tenure-track positions. In the current study, the CQR coding team included two master's students working with the second author to identify illustrative examples of identified themes, with a third master's student serving as an auditor. One master's student identified as a gay, white, male, another as a heterosexual, bi-racial, female, and the third as a heterosexual, white, male. The five-person research team for the current study also identified holding a spiritual identity and significant relationships with religion or spirituality over time. As recommended by Hill, Thompson, and Williams (1997), each researcher described their expectations and beliefs related to the research questions, including identification of potential challenges, areas of concerns, or issues to attend to in the interview and data analysis process. The researchers discussed their biases at the start of the project. All researchers discussed their concerns that sexual orientation change efforts might be discussed by participants and noted their philosophical position opposed to this. One researcher noted his bias that religious and spiritual issues would be handled poorly in counseling with LGB persons, due to his own experiences of this in personal counseling. Another researcher noted her own guilt about not previously handling religious and spiritual issues in counseling according to what is now recognized as best practice. Given the mixed findings in other research, the research team also expressed concern about how the topic of religion or spirituality in counseling might be seen as more distressing and less life-enhancing when discussed by LGB participants. All researchers agreed to continue to journal their thoughts and biases as they progressed through the study and remained committed to exploring this material throughout the project to remain clear and transparent to appropriately collect and analyze data.

\section{Data Analysis}

Data were analyzed using CQR as outlined by Hill et al. (2005). CQR method strategically utilizes a coding team, with attention to variance across identity and perspectives as a means to increase trustworthiness in the study (Goodrich et al., 2016; Hays \& Singh, 2011). From participants' experiences, we examined how they discussed their experience of religious/spiritual counseling, as well as how that appeared to influence their identity development (Goodrich et al., 2016).

After the interviews were assigned, taped and transcribed, the three interviewers reviewed each of the transcripts and open coded them; the interviewer who did not conduct the interview coded the transcript first, followed by the second interviewer who did not interview the participant. The interviewer then open coded the transcript last, with all transcripts being coded and distributed in a round robin fashion until all open coding was finished. The team of interviewers (known in CQR as "judges") then met, via conference call, to discuss their impressions and understandings of the data present in the transcripts one at a time.

A second team of CQR judges, including the second author and two master's students also engaged in coding the transcripts. The two master's students worked together to code the transcripts, and then they met with the second author to argue to confirm, debate, and refine codes until there was consensus across the team. Following this process for each of the transcripts, the first and second author then met for a separate conference call to collapse the open data into larger developed core ideas. Core ideas then were subsumed into conceptual labels, which categorized core ideas into broader categories. After the judges agreed on categories, the third master's student serving as auditor (who sat out all interview and the two-step coding processes) reviewed the core ideas and categories with two untracked, clean transcripts to explore accuracy of the domain and word coding, as well as provide any challenges to the judges regarding agreement with the outcome of the coding and consensus building process. Following receipt of auditor feedback, the authors met as a team to reexamine the data in a cross-analysis process and reach new consensus on word and domain coding. Following protocols for $\mathrm{CQR}$, all data were then classified into categories 
expressing that data was general (categories found in 11-12 transcripts), typical (categories found in 6-10 transcripts) or variant (categories found in 2-5 transcripts; Goodrich et al., 2016; Hays \& Singh, 2011).

\section{Findings}

Participants identified two intersecting cognitive themes as resulting from their exploration of both their LGB and religious and/or spiritual identities within their own counseling. In the first theme, 11 of the 12 participants talked in varied ways about their increased sense of agency and locus of control. In a second general theme, 11 participants described evidence of cognitive development and increased cognitive flexibility.

\section{Agency and Locus of Control}

As noted previously, 11 participants noted an increased sense of agency and locus of control. Participants in this study recognized and described increased agency as occurring across three contexts, including a) intrapersonally, within themselves, b) interpersonally, within the therapeutic relationship, and c) globally, within the various communities to which participants belonged.

Intrapersonally (7; typical). As a typical theme, seven participants described ways they recognized they had increased agency within themselves. Leah described how her involvement in a 12-step program increased her agency and internal locus of control when saying, "The 12 steps, part of that is looking at myself and claiming responsibility for one's life." Applying this when reflecting on her earlier experiences in counseling, she noted, "I think I was closed...I had been in denial for a long time." Having learned the experience of claiming responsibility for one's life, Leah noted the ways in which she could move past her denial to understand her own responsibility in her life and the choices that she could make for a better future.

Gabriel noted that earlier in his identity development process, he had this "big, huge boundary that I put up was there's nothing fundamentally wrong... with me and I'm not gonna [sic] be gay anymore." He went on to say that "I had my own journey through my inability to navigate, negotiating sexual boundaries, which I had." Through his journey, he was able to come to terms with his sexual identity and form healthier boundaries in intimate relationships. By claiming his identity and understanding how his sexual behavior influenced his perception of himself, he discussed being able to move to a healthier life.

Naomi described that the process of identification had to happen slowly, first with herself, and then with selected family members. Even then, she had to be strong, since it would take those selected family members time to adjust to accept her identity. She stated when she first started, "I am not ready to come out to everybody. At first, I told my mom and she was like you know you're not. I was like yes I am. I am who I am and it's not going to change." Although Naomi was able to find the strength to come out to others, she shared that she had an initial challenge with her first experience. Prepared, however, she reported being able to stand in her truth even when her mother doubted her new identity.

Intrapersonal cognitive shifts did not just occur for participants based upon their sexual identity; they also occurred regarding their faith traditions. As such, these participants reported struggling not with their sexual identity, but their religious identity once they understood that they were LGB. In reconsidering her faith tradition, Hope stated

My faith, I really believe that God does have a plan for things and that He intervenes in our lives for different reasons and that He has an impact on the world. The things that happen in the world and around us are at least somewhat influenced by God's plans and his purposes.

Similarly, Rebekah noted that her perception of herself and her spirituality had to change to better reconcile her spiritual and gender identities; "I had to evolve out of that where women were very feminized and actually oppressed and the men had the authority period." Finally, Aaron noted development of a meta-awareness of his religious positionality, saying

That's kind of how I view the world. I view the world in a different way than someone who's Protestant or someone who's Jewish or someone who's Muslim, or whatever that is. Because of that history that I've had, with that faith [Catholicism].

Interpersonally (11; general). Participants also noted ways in which they found agency in their interactions with others; they could not only take responsibility or control over their own lives and actions, but they were also able to claim this in how they interacted with others. In particular, participants spoke about the ways in which they claimed agency in relationship to the counselor or therapist (defined as such by participants) they saw for personal counseling as part of their identity journey. This included their finding or pursuing of a certain counselor as well as their need to switch or terminate a relationship or change how their relationship was functioning in context with their counselor.

Leah most strongly evidenced increased agency and locus of control in talking about her selection of different counselors over her lifetime. She began,

One was picked for me as a result of an assault. That [relationship with the counselor] went absolutely nowhere. Then, the next person [counselor she saw] was probably in my 
late 20s. She was a woman...and then a coworker...referred me to this guy.

She then went on to discuss her selection of a counselor following her involvement in a 12-step program, noting at first, "I found [him] by accident" but then explained that she met him in graduate school since he "was on a list of people that we could to kind of [sic] interview about some favorite topic of ours," and that "when some stuff started coming up very powerfully about my sexual identity, I thought of him." As such, Leah saw counseling as a process, and that at different times, different counselors might serve her in different ways. Leah claimed her agency through whom (which counselor) she wished to work with at different junctures of her life, knowing that each counselor might be able to provide her something different when she was faced with different life challenges.

Hope explored how she made decisions about the counselors she later sought support from:

I think it's imperative that if that's important to you that you seek out somebody that is gonna [sic] help you in the best way...If that means phone interviews or going to speak with a therapist for an initial session and to feel them out about some of those things, that is absolutely imperative that you do that.

Beth had a different experience of finding a counselor, but still found ways to employ her personal agency in the counseling relationship:

I first went to see her when I was in graduate school and training to be a therapist. It was largely because it was one of the requirements of the school, then I was able to find a community of people, you know people that weren't just on television or in a book...I went in deciding I was going to be very open about who I was because that was what I was there to talk about...I really at that stage of my life when I was almost thirty I was...ready to stop being on the fringe and, you know, be at the center and without having to change me.

Gabriel expressed agency in the opposite direction when he discussed his first counseling relationship: "I saw him once and I said I just don't think he's the kind that I don't ever want to talk to again." From the first meeting, Gabriel was able to see that the counselor would not be able to provide him what he needed, or in the way that he needed it. Therefore, the agency he expressed was in ending a counseling relationship. Similarly, Hope also met with a counselor who she initially thought might be useful for her, but experiences in counseling proved otherwise: "I met with a licensed professional counselor and I went there for a number of issues...Ultimately it ended up that I had to terminate that relationship because it just was so uncomfortable. She just couldn't deal with [the issues presented in counseling by Hope] basically, which was unfortunate because I really liked her as a counselor. I had to just do that cuz [sic] I just couldn't address some of my other issues." Hope discussed how the relationship ultimately terminated: "I ended it after things just got too difficult for us to communicate...I just had to go ahead and end it, which I've often went back and forth about, Well, should I have just dealt with it? No, I really shouldn't have." Rebekah also reported facing uncomfortable issues in counseling when she and her counselor disagreed with Rebekah's sexual identity and how Rebekah should behave in the larger world: "So I went the opposite direction. I went and said I'm going to try just about everything. I was like I'm not even going to believe in God that's going to burn me to death and hell. So, I went the complete other direction." Finally, Joseph also expressed experiences with a counselor who did not work for him, but found agency through the experience: "That's really what ended up making me choose to not go back anymoreâǍęI decided that I wasn't really getting much out of it...so it felt liberating because I felt like I was finally making decisions."

Sometimes, participants described how their agency impacted the counseling relationship and discussed how it manifested interpersonally. In his interview, Aaron acknowledged his potential contribution to the therapeutic encounter: "I can look back and know that I'm also an anxious person in general, and so it could be some of my anxiety that played out in terms of that relationship. So, I can own that." Although Aaron discussed how the relationship did not work for him, he saw nuances that it was not just the counselor that did not work in the relationship, but he too played a role in how the therapeutic encounter was experienced.

Globally (5; variant). Finally, a smaller group of participants in the study expressed agency in how they experienced the larger world due to their counseling experience. Each participant explored their personal agencies in their identified community. As an example, Leah discussed how counseling inspired her to take a big step and experience more of the world once she found her personal grounding: "I think it was the only way that the universe could get me to move to New Mexico. I've wanted to live here forever." Anna explored how counseling that addressed her spiritual and sexual identity led her to the field of politics, and how she experienced herself in that larger field:

As I got older, I got more involved in politics in high school. That was my expression, I think, at that time was getting involved in the anti-war movement and the peace movement. My spirituality and my values came through that way more. 
She continued, "For more social support and roots, since I don't have any family left now, I've been active more in the Unitarian church. I identify myself as Unitarian if other people are Unitarian." She later expounded that being Unitarian allowed her the opportunity to combine her spiritual and political lives together as that was her typical experience of the Unitarian Church environment. She further reported that this also allowed her greater opportunities to integrate and openly live as a queer person in her spiritual community.

Hope discussed how counseling led her to her future professional career, as well as informed her how she might interact with others within that profession:

Being a professional counselor, I just really am like I consider myself a professional. I have an identity. I have to be careful about what I say and do. I just feel like that I do need to be picky and that I need to be careful about who I'm with and they need to understand my concerns

Finally, Aaron identified the impact of his prior counseling experiences on the choices he makes now:

It does color how I think about raising spiritual themes [in his own work as a counselor]. Both places that I've worked since this experience do identify as either highly religious or highly spiritual. It's something people do think about raising in their counseling sessions.

\section{Cognitive Development and Cognitive Flexibility}

Eleven participants identified three contexts wherein their cognitive development took place and resulted in increased cognitive flexibility, including a) intrapersonally, related to increased differentiation in self-concept, b) interpersonally, related to increased differentiation of beliefs within their religious and/or spiritual communities, and c) globally, related to increased integration of information resulting in more critical thinking.

Intrapersonally (6; typical). Six participants explored how they experienced cognitive development intrapersonally, related to increased differentiation in their self-concept. Leah described an example of her cognitive development when it was dualistic, recalling, "I had moments where a reframe might have taken me a minute to look at. Most of it was just soâĂęmost of the things people shared with me, like insights, really helped me tremendously." In this quote, Leah notes that she recognized that previously, she would not have been able to accept a reframe immediately, and now, following counseling, she could accept two sides. Similarly, at the start of the counseling relationship, Isaiah too had a dualistic understanding of the world: "I could see nothing divine in being gay. Therefore, it was a flaw or something that was a temporary condition, and therefore by being a condition it was correctable." Gabriel similarly echoed the experience that Isaiah had shared:

Spiritual counseling cut us off from-because it's not us, it's the devil, it's Satan, it's the enemy, it's flesh so it really isn't you. Then you never learn to embrace the thing that youâÁŹre afraid of. You never learn to create a boundary to protect yourself. You never learn to negotiate or navigate when you are sexually active in same sex relationships.

Finally, Rebekah expressed similar concerns related to her early identity development experience: "Then I automatically thought I was going to hell. I prayed for six years without ceasing. I wouldn't act on it and wouldn't even mention the word gay. I couldn't accept it...after I acted on my feelings I still had some issues thinking about whether I was going to hell or not." Here, Rebekah spoke about identity as feeling/thought versus behavior, and again spoke retrospectively about having been more dualistic. She later shared that over time, her views evolved from an either/or view of religion to a more flexible understanding.

With time, participants began to notice a shift or change in how they thought about themselves, or the cognitive flexibility that they had. Naomi described how she initially needed to adjust her spiritual experience in the opposite direction (from belief to nonbelief) when attempting to resolve the conflict between her sexual and spiritual identities, but then was able to come to a point of acceptance and integration: "I didn't believe and just went with the flow and as I got a little bit older I kind of got more independent and grew and just grew into my beliefs how I have now." Beth discussed a similar change when she stated, "developmentally I was just ready to change on every level."

In talking about his cognitive development and cognitive flexibility, Aaron noted that early on, "I took a very rigid or a very dualistic view of the world.... and this is the only way anyone is ever going to look at this." He went on to describe the development of relativistic thinking when noting differences between his thinking and that of his counselor, "I defined myself as a Catholic, although not practicing all things in the sort of traditional sense. She really kept on coming back to that. Every single session, actually." He later reported that this later served as a barrier in his relationship with his counselor, but he was able to own a different interpretation of his experience and hold his two distinct identities together even when challenged by others.

Interpersonally (8; typical). Eight participants noted that they had cognitive development changes interpersonally, related to increased differentiation of beliefs within their religious and/or spiritual communities. A number of the participants discussed their shifting beliefs from the spiritual system from which they grew up. As an example, Gabriel 
stated, "These things happen and I have a different idea of what that is now." Naomi further explained that now when she interacts with people from her faith tradition with whom she disagrees, she holds firm to the idea that "I have my beliefs and you have your beliefs." Hope explained her process of differentiation with a bit more detail, explaining how she distinguishes herself from her religion of origin:

I was like, don't talk to me about this God can fix everything. That God has a plan. I believe some of that stuff myself, but when you're angry and you're hurting because you've had so many losses and you've had-I've had a lot of losses but I've also had a lot of trauma in my life. I think it's okay for me to question.

She later expanded upon how she now views her spirituality: "what I believe and how I function in this world is to kinda [sic] go about my life in terms of being caring and concerned and trying to help others."

Not all participants had to take a one or the other view on their spirituality, however. Leah reflected on her growth in counseling and articulated a relativistic view: "I think part of it [her shift] was a recognition of some kind of guiding power that even got me to go to AA. I can look back and see things that happened in my life that allowed me be open to sitting in a room and talking about God, when I was not believing in God or angry at God, or whatever." Thus, Leah was able to find her own interpretation of her spirituality not through her original church, but a 12-step program, and integrate the spiritual components from that program to better fit her own lived experience.

Participants did not report interpersonal development only in their religious experiences; some also reported this development as part of the counseling relationship. Aaron displayed how his relativistic thinking impacted his therapeutic relationship when continuing to describe his differing formulation of his Gay and Catholic identities as compared to that of his counselor, saying:

I honestly think she genuinely felt for me and felt like she was helping me; like I was doing something hurtful against myself in terms of holding this identity. Although, I explained to her, kind of like I explained to you, I don't and I didn't practice traditional Catholicism in the most strictest [sic] of terms. I think her intention was to be helpful and caring and to ensure I had a healthy self-image or self-identity, or whatever that was. I think she really missed the boat in terms of how I define myself and how I practice that.

Joseph provided deeper context to this idea when he explained why he ultimately explored a counseling relationship to better understand his sexual and spiritual identities:
I think my intention was to get an outsider's view, to either be told whether it was wrong or right. I think I had been so in my head for so long in trying to deal with things on my own and not having any clear answer that I wanted somebody to give me a clear and concrete answer. Somebody who didn't really have an investment in things. I didn't want to hear it from a pastor. I didn't want to hear it from anybody who-I don't know who I wanted to hear it from. I just wanted something concrete in front of me that people who wouldn't have a lot of investment could tell me. I felt they could be more honest.

Globally (7, typical). Finally, a typical theme found in participants' narratives included global cognitive development, which was defined as increased integration of information resulting in more critical thinking. One example is Isaiah, who spoke about the suicidal ideation he had following his experiences in conversion/reparative therapy due to his evangelical Christian spirituality and experience of queer attraction.

I finally came to a point where I determined okay, this isn't working. Everything you've been taught and told is not working. I began to have suicidal thoughts where I thought the only way I'm gonna [sic] end this is if I take my life. I thought I have got to find a way to do this so that it looks like an accident because it was a real concern. I had four children. I did not want my children spending the rest of their lives going to counseling so that they can come to terms with their dad's suicide. I spent some time planning it out.

Isaiah then spoke about moving through his identity conflict through the experience of his suicide planning. He knew that suicide would not be an option because of his family, so he would need a new way to move through the world. He began the process of coming to terms with his sexual identity, and later, found a new spiritual identity that better fit his needs.

Anna also spoke about finding a new spirituality and being okay if others did not understand or find the same meaning in her spiritual experiences. She explained "I mean, I can translate into other things if there's something they make or do that I don't have an association with, I mean, I can figure out what-like the spirit animal or guide is just something to connect to as an assistant. I do that, I just don't necessarily do it the way that somebody else might understand it." Similarly, Hannah discussed the need to hold to her own experience, even when others did not understand or criticized her new identity: 
The other day I had a friend of mine who told me that she feels my relationship is a sin and gave me a whole long discussion. I was actually able to handle the situation fine. I didn't cry about it. It bothered me but I was able to say this is how she feels and this is not how I feel. I was able to talk with my partner about it and kind of not get so despairing about it. That's what I mean with a good day. When I was able to handle the hateful things that are said and the negativity, and that kind of thing. Not that it won't affect me but I will be able to handle it better than I would have in the past

Hope reported facing similar experiences with conservative members of her familial and social environments, and learning to respond in new and different ways: "I've had to obviously adapt over the years from a more conservative viewpoint to being more open and more holistic about my choices and things because I realize that's who I am. I can't really change that. I've tried. I think I've tried to change it but I can't. I've tried to deny it but it's just there."

Beyond learning new and different ways to respond to others, some participants discussed new ways that they sought to think about and integrate understandings about themselves, as well as where they put their energies. As Beth noted,

I just kept selecting the community that would that would validate me...each time I put myself in a community, I was more and more integrated, and...you know and it's like now I can sit around in a room with a group of straight colleagues and if the question comes up about our difference, then I'll say sure you want to know anything.

Similarly, Joseph explained, "Now I've opened up to everything. I feel like I have a better understanding of what it's really supposed to be about and not all of these rules and political beliefs." Finally, in exploring a better synthesis of which he felt he was, Aaron described the integration of his Gay and Catholic identities, reflecting increased cognitive flexibility and integration of critical thought. He noted, "There were a number of priests who actually privately identified as gay" who

helped me develop more of a spiritual identity and a religious identity, a Catholic identity while still being gay. So, where I didn't attend traditional Mass my freshman year, later in my sophomore year and through my senior year I both attended Mass and actually used to do the first reading or the second reading for the church.

\section{Discussion}

The current study suggests that agency and locus of control, as well as cognitive development and increased cognitive flexibility, may be evident in the reports of LGB clients who addressed religious/spiritual concerns in counseling. More specifically, findings also demonstrated that participants described enacting both of these themes differentially across intrapersonal, interpersonal, and global domains. Participants described agency and locus of control as typical $(n=7)$ at the intrapersonal level, general $(n=11)$ at the interpersonal level, and variant $(\mathrm{n}=5)$ at the global level. Likewise, participants described cognitive development and increased cognitive flexibility as typical $(n=6)$ at the intrapersonal level, typical $(\mathrm{n}=8)$ at the interpersonal level, and typical $(\mathrm{n}=8)$ at the global level.

The findings of the increased agency and internal locus of control support earlier research that has noted the association of both with increased psychological functioning (Aldwin et al., 2017; Carter et al., 2014; Holt et al., 2003; Schultz \& Schultz, 2004). Although not examined to date, one might expect LGB individuals to have higher levels of psychological functioning and thereby further research is needed to distinguish the temporal relationships involved. As of yet, however, it remains uncertain if there is a causal relationship between psychological functioning and agency and internal locus of control or vice versa. Future research should address if any such relationship may exist.

The findings of differential enactment of agency and internal locus of control across the intrapersonal, interpersonal, and global level add to the complexity of our understanding. In discussing her own experiences with counseling in Critchfield and Pula (2015), author Alison Bechdel articulated that as "an individual approach, it [counseling] has great political power. To help people access their own autonomy and agency is as political as it can get" (p. 402). Future research can, however, explore potential developmental differences in the emergence and enactment of agency and internal locus of control across contexts. It is our belief that it is possible that similar to other developmental differences in this domain (Bandura, 2001), agency and internal locus of control first appear interpersonally with the counselor's support, then intrapersonally, and lastly more globally.

The findings of cognitive development and increased cognitive flexibility also support earlier scholarship that noted the complexities in "creating safe spaces in treatment that allow for an exploration of fantasy, creativity, and selfdetermination, while simultaneously being capable of formulating our patient's problems and developmental histories in such a way as to identify troubling emotional symptoms or maladaptive compromises that are tied up in concerns of gender and sexuality" (Critchfield \& Pula, 2015, p. 409). While affirmation, self-disclosure, and skill-building in response to minority stress have all been identified as potentially useful 
in work with LGBTQ clients (Porter et al., 2014), reframing may provide a particular benefit because it has been implicated as a specific intervention skill that can assist in disrupting false dichotomies and expand one's frame of reference in other contexts with other populations (Buser et al., 2011; Goodrich et al., 2016). The current study cannot identify what specifically accounted for participants' cognitive development; however, future research could examine the impact of specific therapeutic approaches, theoretical frames, and specific counseling skills (e.g., reframing) on clients' cognitive development and increased cognitive flexibility.

It is of interest that participants reported relatively equal manifestation of cognitive development and increased cognitive flexibility across contexts, being enacted as typical $(n=6)$ at the intrapersonal level, typical $(n=8)$ at the interpersonal level, and typical $(\mathrm{n}=8)$ at the global level. Although no prior research could be identified with heterogeneous client samples for comparison, there is some suggestion in prior research that LGB clients may have unique experiences with heterosexism and homophobia prior to and within counseling (Robertson, Pote, Byrne, \& Frasquilho, 2015 ) that, as a component of minority stress, could arguably inhibit some aspects of cognitive development in LGBT individuals, restricting cognitive flexibility specifically. Thus, one possible explanation for how typical this theme evidenced across intrapersonal, interpersonal, and global contexts is that when an LGB individual experiences a counseling relationship with lower levels of heterosexism and homophobia, there is a rebound effect and cognitive development intensifies. Future research could incorporate pre- and postmeasures of cognitive complexity across both heterogeneous and LGB samples in counseling.

\section{Limitations}

As with all descriptive qualitative research, caution is needed in interpreting the current research results or extending the findings to other populations. The small, self-selected convenience sample of LGB participants does not represent the perspectives and experiences of the trans or queer communities within the collective LGBTQ population. While the current sample represented some diversity regarding age, gender, and geographic region, it had minimal racial and ethnic diversity. Thus, it is unknown how similar or different these 12 participants were to other LGB individuals who seek counseling, or to those clients whose counseling experiences did not address religious or spiritual concerns, especially those outside of Christian traditions. Further, although this CQR analysis adhered to the methodological steps outlined by Hill et al. (2005) and incorporated additional trustworthiness checks recommended by Hays and Singh (2011), there is nonetheless risk of researcher bias. In particular, the researchers recognized a priori that consistent with research and their earlier personal and professional experiences, they held tentative assumptions that religious or spiritual counseling may have been mishandled in most counseling settings with LGB persons. These assumptions were monitored through the research process, and researchers journaled after interviews to ensure that they kept that bias in check. They also ensured that the semi-structured interview protocol employed in the study specifically addressed positive and lifeaffirming experiences through religious and spiritual counseling to ensure that participants had explicit opportunities to speak about both positive and negative experiences. Finally, use of auditors also supported that results were data driven and findings reflected participants' expressed experiences.

\section{Implications}

There are several implications for the findings from this study that includes two primary and intersecting themes of increased agency and locus of control, as well as increased cognitive flexibility across intrapersonal, interpersonal, and global domains. Although this study did not explore or establish a temporal sequence for increased client agency and locus of control, counselors may still find it beneficial to formally or informally assess both agency and locus of control throughout their work with LGB clients who also identify as religious or spiritual. Regardless of presenting issue, it is feasible to establish treatment goals for increased agency and locus of control at the intrapersonal, interpersonal, and global levels because of prior association with increased psychological functioning (Aldwin et al., 2017; Carter et al., 2014; Critchfield \& Pula, 2015; Holt et al., 2003; Schultz $\&$ Schultz, 2004). Toward this end, counselors can consider incorporating specific interventions aimed at addressing client agency and locus of control (Goodrich et al., 2016) as part of overall treatment. Moreover, the reported prominence of increased cognitive flexibility in this study and the prior research that associates this with positive mental health outcomes (Brewster et al., 2013) warrant counselors' use of counseling skills that have been demonstrated to expand client perception and challenge dichotomous thinking such as reframing and raising discrepancy (Buser et al., 2011; Goodrich et al., 2016).

Counselors, as well as counselor educators and supervisors, should consider the how in this study, LGB clients described therapeutic ruptures resulting from counselors focusing more on the counselor's concerns than those reported by the client. Specifically, clients described an over focus in the counseling relationship around one aspect of client's sexual/affectional orientation or spiritual identity which was perceived by clients as being more about the counselors' 'own stuff,' than it was the client's goals. Accordingly, counselors, counselor educators, and supervisors can review the ACA Code of Ethics (2014) concerning therapeutic interactions with clients and commit to avoiding untested or harmful therapeutic models, such as sexual orientation change 
efforts. Also, counselors, counselor educators and supervisors should also acknowledge the multicultural/diversity statement of the Code of Ethics (2014), which speaks to both a person's affectional orientation and religious/spiritual identity and reflect on how to assimilate both in their work, as well as counseling competency documents by the Association for Lesbian, Gay, Bisexual, and Transgender Issues in Counseling (ALGBTIC; ALGBTIC LGBQQIA Competencies Taskforce et al., 2013; Burnes et al., 2010). Lastly, counseling training programs are asked to consider how to address counselor bias so that clinicians can better work past their issues to be present and focus on the needs of the client whom they are serving.

\section{Conclusions}

The present study was a qualitative exploration of 12 participants who identified as LGB and received counseling that addressed religious/spiritual issues. Participants identified two primary and intersecting themes, including an increased sense of agency and locus of control, as well as increased cognitive flexibility. Through intrapersonal, interpersonal, and global experiences, each participant addressed how they grew in their sense of self and identity through their counseling and personal experiences. The findings of the study support that persons can hold intersecting identities as LGB and religious or spiritual. There are therapeutic opportunities that address this in counseling, as long as the personal concerns or biases of the counselor do not work to negatively influence the therapeutic process.

\section{References}

Aldwin, C. M., Igarashi, H., Gilmer, D. F., \& Levenson, M. R. (2017). Health, illness, and optimal aging: Biological and psychosocial perspectives. Springer Publishing Company.

ALGBTIC LGBQQIA Competencies Taskforce, Harper, A., Finnerty, P., Martinez, M., Brace, A., Crethar, H. C., ... Hammer, T. R. (2013, January). Association for lesbian, gay, bisexual, and transgender issues in counseling competencies for counseling with lesbian, gay, bisexual, queer, questioning, intersex, and ally individuals. Journal of LGBT Issues in Counseling, 7(1), 2-43. doi:10.1080/15538605.2013.755444

American Counseling Association. (2014). Code of ethics. Author.

Anderton, C. L., Pender, D. A., \& Asner-Self, K. K. (2011). A review of the religious identity/sexual orientation identity conflict literature: Revisiting festinger's cognitive dissonance theory. Journal of LGBT Issues in Counseling, 5(3-4), 259 - 281.

Bandura, A. (2001). Social cognitive theory: An agentic perspective. Annual Review of Psychology, 52, 1-26.
Beagan, B. L., \& Hattie, B. (2015, April). Religion, spirituality, and LGBTQ identity integration. Journal of LGBT Issues in Counseling, 9(2), 92-117. doi:10.1080/15538605.2015.1029204

Bowland, S. E., Foster, K., \& Vosler, A. N. R. (2013, October). Culturally competent and spiritually sensitive therapy with lesbian and gay christians. Social Work, 58(4), 321-332. doi:10.1093/sw/swt037

Bozard, R. L., \& Sanders, C. J. (2011, February). Helping christian lesbian, gay, and bisexual clients recover religion as a source of strength: Developing a model for assessment and integration of religious identity in counseling. Journal of LGBT Issues in Counseling, 5(1), 47-74. doi:10.1080/15538605.2011.554791

Brendel, J. M., Kolbert, J. B., \& Foster, V. A. (2002).

Journal of Adult Development, 9(3), 217-227. doi:10.1023/a:1016056227344

Brewster, M., Moradi, B., DeBlaere, C., \& Velez, B. (2013). Navigating the borderlands: The roles of minority stressors, bicultural self-efficacy, and cognitive flexibility in the mental health of bisexual individuals. Journal of Counseling Psychology, 60(4), 543-556. doi:10.1037/a0033224

Burnes, T. R., Singh, A. A., Harper, A. J., Harper, B., Maxon-Kann, W., Pickering, D. L., ... Hosea, J. (2010). American counseling association: Competencies for counseling with transgender clients. Journal of LGBT Issues in Counseling, 4(3-4), 135 - 159.

Buser, J. K., Goodrich, K. M., Luke, M., \& Buser, T. J. (2011, July). A narratology of lesbian, gay, bisexual, and transgender clients' experiences addressing religious and spiritual issues in counseling. Journal of LGBT Issues in Counseling, 5(3-4), 282-303. doi:10.1080/15538605.2011.632395

Carter, L., Mollen, D., \& Smith, N. (2014). Locus of control, minority stress, and psychological distress among lesbian, gay, and bisexual individuals. Journal of Counseling Psychology, 61(1), 169-175.

Critchfield, A. R., \& Pula, J. (2015, July). On psychotherapy, LGBT identity, and cultural visibility: In conversation with alison bechdel. Journal of Gay $\mathcal{G}$ Lesbian Mental Health, 19(4), 397-412. doi:10.1080/19359705.2015.1046202

Crowell, K. A., Galliher, R. V., Dehlin, J., \& Bradshaw, W. S. (2014, October). Specific aspects of minority stress associated with depression among LDS affiliated nonheterosexual adults. Journal of Homosexuality, 62(2), 242-267. doi:10.1080/00918369.2014.969611

Dahl, A. L., \& Galliher, R. V. (2012). Lgbtq adolescents and young adults raised within a christian religious context: Positive and negative outcomes. Joural of Adolescence, 35(6), 1611-1618.

Deci, E. L., Hodges, R., Pierson, L., \& Tomassone, J. (1992, 
August). Autonomy and competence as motivational factors in students with learning disabilities and emotional handicaps. Journal of Learning Disabilities, 25(7), 457-471. doi:10.1177/002221949202500706

Dehlin, J. P., Galliher, R. V., Bradshaw, W. S., \& Crowell, K. A. (2015, January). Navigating sexual and religious identity conflict: A mormon perspective. Identity, 15(1), 1-22. doi:10.1080/15283488.2014.989440

Goodrich, K. M., Buser, J. K., Luke, M., \& Buser, T. J. (2016). Spiritual and sexual identity: Exploring lesbian, gay, and bisexual clients' perspectives of counseling. Journal of Homosexuality, 63(6), 783-807. doi:10.1080/00918369.2015.1112192

Granello, D. H. (2002, June). Assessing the cognitive development of counseling students: Changes in epistemological assumptions. Counselor Education and Supervision, 41(4), 279-293. doi:10.1002/j.15566978.2002.tb01291.x

Green, M. S., Murphy, M. J., \& Blumer, M. L. C. (2010, October). Marriage and family therapists' comfort working with lesbian and gay male clients: The influence of religious practices and support for lesbian and gay male human rights. Journal of Homosexuality, 57(10), 1258-1273. doi:10.1080/00918369.2010.517072

Hays, D. G., \& Singh, A. A. (2011). Qualitative inquiry in clinical and educational settings. The Guilford Press.

Hays, D. G., \& Wood, C. (2011, July). Infusing qualitative traditions in counseling research designs. Journal of Counseling $\mathcal{E}$ Development, 89(3), 288-295. doi:10.1002/j.1556-6678.2011.tb00091.x

Hill, C. E. (2011). Consensual qualitative research: A practical resource for investigating social science phenomena. American Psychological Association.

Hill, C. E., Knox, S., Thompson, B. J., Williams, E. N., Hess, S. A., \& Ladany, N. (2005). Consensual qualitative research: An update. Journal of Counseling Psychology, 52(2), 196 - 205.

Hill, C. E., Thompson, B. J., \& Williams, E. N. (1997, October). A guide to conducting consensual qualitative research. The Counseling Psychologist, 25(4), 517572. doi:10.1177/0011000097254001

Hofer, B. K., \& Pintrich, P. R. (1997). The development of epistemological theories: Beliefs about knowledge and knowing and their relation to learning. Review of Educational Research, 67(1), 88-140.

Holt, C. L., Clark, E. M., Kreuter, M. W., \& Rubio, D. M. (2003). Spiritual health locus of control and breast cancer beliefs among urban african american women. Health Psychology, 22(3), 294-299.

Kim, B. S. K., \& Omizo, M. M. (2006, April). Behavioral acculturation and enculturation and psychological functioning among asian american college students. Cultural Diversity and Ethnic Minority Psychology, 12(2),
245-258. doi:10.1037/1099-9809.12.2.245

Knox, S., Catlin, L., Casper, M., \& Schlosser, L. Z. (2005, July). Addressing religion and spirituality in psychotherapy: clients' perspectives1. Psychotherapy Research, 15(3), 287-303. doi:10.1080/10503300500090894

Kocet, M. M., Sanabria, S., \& Smith, M. R. (2011, July). Finding the spirit within: Religion, spirituality, and faith development in lesbian, gay, and bisexual individuals. Journal of LGBT Issues in Counseling, 5(34), 163-179. doi:10.1080/15538605.2011.633060

Lalich, J., \& McLaren, K. (2010, October). Inside and outcast: Multifaceted stigma and redemption in the lives of gay and lesbian jehovah's witnesses. Journal of Homosexuality, 57(10), 1303-1333. doi:10.1080/00918369.2010.517076

Luke, M., \& Goodrich, K. M. (2015). Working with family, friends, and allies of lbgt youth. Journal for Social Action in Counseling $\mathcal{E}$ Psychology, 7(1), 63-83.

Luke, M., Goodrich, K. M., \& Gilbride, D. D. (2013). Intercultural model of ethical decision making: Addressing worldview dilemmas in school counseling. Counseling and Values, 58(2), 177-194. doi:10.1002/j.2161007x.2013.00032.x

McGlasson, T. D., \& Rubel, D. J. (2015, April). My soul to take: A phenomenology of the struggle for an authentic gay spirituality. Counseling and Values, 60(1), 14-31. doi:10.1002/j.2161-007x.2015.00058.X

Nadal, K. L., Skolnik, A., \& Wong, Y. (2012, January). Interpersonal and systemic microaggressions toward transgender people: Implications for counseling. Journal of LGBT Issues in Counseling, 6(1), 5582. doi:10.1080/15538605.2012.648583

Perry Jr., W. G. (1970). Forms of intellectual and ethical development in the college years: A scheme. Holt, Rinehart, and Winston.

Perry Jr., W. G. (1998). Forms of ethical and intellectual development in the college years: A scheme. JosseyBass.

Pitt, R. N. (2009, December). "Still looking for my jonathan": Gay black men's management of religious and sexual identity conflicts. Journal of Homosexuality, 57(1), 39-53. doi:10.1080/00918360903285566

Pitt, R. N. (2010, March). "Killing the messenger": Religious black gay men's neutralization of anti-gay religious messages. Journal for the Scientific Study of Religion, 49(1), 56-72. doi:10.1111/j.14685906.2009.01492.x

Porter, J., Hulbert-Williams, L., \& Chadwick, D. (2014, October). Sexuality in the therapeutic relationship: An interpretative phenomenological analysis of the experiences of gay therapists. Journal of Gay $\mathcal{F}$ Lesbian Mental Health, 19(2), 165-183. 
doi:10.1080/19359705.2014.957882

Robertson, J., Pote, H., Byrne, A., \& Frasquilho, F. (2015). The experiences of lesbian and gay adults on acute mental health wards: Intimate relationship needs and recovery. Journal of Gay $\mathcal{E}$ Lesbian Mental Health, 19(3), 261-284. doi:10.1080/19359705.2014.998800

Rosenkrantz, D. E., Rostosky, S. S., Riggle, E. D. B., \& Cook, J. R. (2016, June). The positive aspects of intersecting religious/spiritual and LGBTQ identities. Spirituality in Clinical Practice, 3(2), 127-138. doi:10.1037/scp0000095

Rostosky, S. S., Danner, F., \& Riggle, E. D. B. (2010, August). Religiosity as a protective factor against heavy episodic drinking (hed) in heterosexual, bisexual, gay, and lesbian young adults. Journal of Homosexuality, 57(8), 1039-1050. doi:10.1080/00918369.2010.503515

Rotter, J. B. (1954). Social learning and clinical psychology. Prentice-Hall, Inc. doi:10.1037/10788-000

Schultz, D. P., \& Schultz, S. E. (2004). Theories of personality. Wadsworth Publishing.

Shelton, K., \& Delgado-Romero, E. A. (2011). Sexual orientation microaggressions: The experience of lesbian, gay, bisexual, and queer clients in psychotherapy. Journal of Counseling Psychology, 58(2), 210221. doi:10.1037/a0022251

Sherry, A., Adelman, A., Whilde, M. R., \& Quick, D. (2010). Competing selves: Negotiating the intersection of spiritual and sexual identities. Professional Psychology: Research and Practice, 41(2), 112-119. doi:10.1037/a0017471

Streufert, S., \& Swezey, R. W. (1986). Complexity, managers and organizations (organizational and occupational psychology). Academic Pr.

Thompson, L. K., \& Luke, M. M. (2016). Examining selfdetermination theory in the clinical supervisory context. Romanian Journal of Counseling, 2(1), 30-52.

Welfare, L. E., \& Borders, L. D. (2010, March). Counselor cognitions: General and domain-specific complexity. Counselor Education and Supervision, 49(3), 162-178. doi:10.1002/j.1556-6978.2010.tb00096.x 